\title{
DESIGN, OPTIMISATION AND CONSTRUCTION OF A PROTOTYPE FOR A THERMOCHROMIC TROMBE WALL
}

\author{
Fernando Martín-Consuegra, Carmen Alonso, Gloria Pérez, Borja Frutos, Ana \\ Guerrero, Ignacio Oteiza (1)
}

(1) Instituto Eduardo Torroja de ciencias de la construcción, CSIC. Madrid (SPAIN)

\begin{abstract}
Most of the existing buildings in Spain lack of any thermal insulation in their envelope. They are on urgent need to be refurbished to reduce their energy consumption to meet compliance with current European Directives. The standard solution for the rehabilitation of facades incorporate thermal insulation materials to reduce heat transmission. The work presented here proposes an extension of the conventional approach: the installation of Trombe walls on sunny facades incorporating an outer layer of thermochromic mortar in the external surface. The Thermochromic Trombe Wall (TTW) is a new system optimizing the traditional Trombe wall with addition of the thermochromic coatings (TCC). This improves the energy performance of existing buildings by enhancing their solar gains. This paper describes the design and configuration of the new TTW system. While traditional solutions can be evaluated with a simple heat transfer equation, a complex energy model is needed to evaluate TTW.
\end{abstract}

An energy simulation technique is used to determine parameters that influence thermal performance. The thermochromic mortar transition temperature is designed in such a way as to achieve maximum efficiency. The results obtained from the parametric study were used to determine aspects for the construction of a first prototype on a laboratory test cell.

The information obtained from the experiment will be used for the calibration of the energy model that will establish the potential for the incorporation of the TTW on existing buildings.

Keywords: Energy refurbishment, passive solar heating; surface optical characteristics 


\section{INTRODUCTION}

This paper presents development of solutions for the refurbishment of inefficient existing buildings to lower the greenhouse gas emissions associated with their energy consumption. In the city of Madrid, climatic conditions together with the poor thermal quality of a large part of existing buildings are the cause of an abnormal high heating energy demand during the winter. Solar energy can be used in facades for the improvement of buildings energy efficiency. Passive solar constructive building systems target the reduction of the energy demand. Low-energy buildings today improve on passive solar design by incorporating a thermal storage and delivery system (Torcellini and Pless, 2004). Existing constructions already contain a certain thermal mass which could be used on these purposes by its incorporation on devices such as the Trombe wall.

\subsection{Trombe wall general description}

The Trombe Wall is an indirect passive solar heating system. Edward Morse patented the design in 1881 but this was ignored until 1964. In the 1960s the design was popularized by constructions that used the principles of passive solar houses in Font-Romeu, Odeillo (France), by the engineer Felix Trombe and the architect Jacques Michel. A Trombe wall is a glazed-wall facing the sun (to the south in the northern hemisphere). Also known as "storage walls" and "solar heating walls" (SHW), they can be adapted to various climates, purposes, and seasons. (Saadatian et al., 2012).

The system is built with materials that can accumulate heat, combined with an air space and a glass surface. The Trombe wall works by absorbing solar radiation from the outside and transferring this heat through the wall by conduction. One may add ventilation holes in the wall to deliver the heat to the room, by convection during the solar radiation time. When solar radiation stops, the inertia of the wall starts delivering accumulated heat.

The storage element usually consists of a masonry wall with thickness between 20 and 40 $\mathrm{cm}$ (heat accumulating wall mass), and a glass surface. The glass is placed from 20 to $150 \mathrm{~cm}$ from the wall, to generate an air chamber. In general, the walls are built with elements of low thermal diffusivity so that a cost-effective storage of energy during the day is achieved. During the night, heat is transmitted through a slow process to the interior of the inhabited space. Additionally it is possible to incorporate a dark surface on the wall on the outside to absorb solar radiation (Martín-Consuegra, 2012).

The short-wave solar radiation traverses the glass and reaches the wall. Greenhouse effect is caused by the opacity to the long wave radiation emitted by the wall. As a consequence, the air in the chamber is heated. In the original version of the Trombe wall, two sets of holes in the wall were included. One in the upper part to connect air chamber to the room and another in the base of the wall to deliver air from the room to the air chamber. In this way the convective loop is created, which circulates the cold air of the room to the air chamber, warms up, and re-enters the interior of the room. 
Additional accessories, such as insulation, shading devices, vents or fans can be used to improve its energy efficiency. Moreover, the parameters for the opaque wall composition contribute to the effectiveness of the system, improving the wall heat storage (high storage capacity), convection, and conduction (insulation, avoiding reverse heat transfer). The coating material is another important component for the system performance. A study in Turkey revealed that the annual heat gain varied from $26.9 \%$ to $9.7 \%$ for concrete, $20.5 \%$ to $7.1 \%$ for brick and $13.0 \%$ to $4.3 \%$ for aerated concrete according to surface colour (Özbalta and Kartal, n.d.).

\subsection{Some recent innovation on Trombe walls}

Recent research on Trombe walls explores the possibilities of including new technologies on this classical system. Most of this research has been performed in China.

In one case some photocatalytic materials were placed inside the air chamber. The objective is to improve indoor air quality by removing indoor formaldehyde. Under solar radiation, ultraviolet light is absorbed by the photocatalytic layer to activate the photocatalytic oxidation of formaldehyde, and the rest of visible and infrared parts are collected by the absorber plate to heat indoor environment. A model based in heat and mass transfer equations is proposed. The amortisation period of the investment for a Trombe wall system made in Hefei, China was calculated to take about 12.1 years based on energy saving (Yu et al., 2018). In another case a Trombe wall was used to equalize in the passive solar house the indoor humidity (Chen et al., 2006).

The energy performance of the system could be improved by adding on the solar protection some building-integrated photovoltaics system (BIPVs). This solution could reduce the lifecycle costs of building construction while generating energy. In this regard, photovoltaic integrated shading devices constitute an important part of BIPVs and play a role in generating power by transforming the unwanted radiation. Generated electricity can be used for reducing cooling energy consumption. These factors are cooling energy consumption, artificial lighting energy consumption, electrical energy generating, indoor visual comfort, and others. The current body of knowledge on photovoltaic integrated shading devices is systematically summarized by (Zhang et al., 2018).

The amount of heat accumulated by the collector wall depends on the specific heat of the materials and the thickness of the wall. On existing buildings, possibilities of changing the composition of the walls are limited. Yet, some additional layers as the thermochromic coating can be added. Some experiments have been developed to try to replace the mass of the wall with some other type of material. Numerical calculations showed that a concrete-water-concrete mixed thermal storage wall was more desirable than a pure water or pure concrete mass Trombe wall for providing excellent thermal comfort in buildings (Kaushik and Kaul, 1989). The system achieved more thermal efficiency as well as fast response for charging and discharging processes as compared to the conventional Trombe walls (Mohamad et al., 2019). This kind of solution could not be suitable for existing buildings.

Recent research in China has already incorporated PCMs to a Trombe Wall, evaluating the year-round thermal performance of the system using an experimentally validated model. The impact of the transition temperature of PCMs and air change rate on cooling and heating load 
were determine, concluding that the contribution is higher in the cooling load (14.8\%) than on the heating load $(12.7 \%)$ when fusion temperatures of PCMs in exterior and interior PCM wallboards were $26^{\circ} \mathrm{C}$ and $22^{\circ} \mathrm{C}$, respectively (Zhou and Wah Yu, 2019).

Yet, no existing research has been found on the incorporation of Thermochromic Coatings on Trombe walls. Proposed here innovative system includes the incorporation of a Thermochromic Coating (TCC) with optical response to solar radiation changing with temperature in order to enhance solar radiation absorption during the winter, while reducing it during the summer periods (Pérez et al., 2019). The details of the optimisation of the material characteristics of the coating are described in the article (Perez et al, in this publication).

\subsection{Objectives}

The main objective of this research is the development of a new construction system for the energy refurbishment of existing buildings. Adding passive solar building systems to existing building may be an alternative or extension to the intensive use of external thermal insulation systems.

Thermochromic Trombe Wall (TTW) system includes the incorporation of a thermochromic coating (TCC) on the original wall. The new coating should enhance solar radiation absorption during the winter, while reducing it during the summer periods (Pérez et al., 2019).

The influence on the energy demand of buildings of external coating parameters (such as visible and solar reflectance) for different façade orientations has been previously studied by (Gavira et al., 2018). The results of this study showed that southern oriented façades are, in principle, not suitable for the incorporation of TTC. The reason is that high solar radiation incidence on south façades during the winter highly increases surface temperature. This circumstance causes the change of the characteristics of the mortar to high reflectance despite the low external air temperatures, avoiding solar radiation uptake when most needed. The inclusion of a controlled ventilation system on the air chamber of the TTW permits to control surface temperature of TTC. This allows achieving maximum efficiency during the winter. The inclusion of controlled ventilation transforms the solution into a parietodynamic wall. In this system, heat transfer by convection is increased, reducing heat transfer by conduction.

The specific objective of this paper is the parametric definition of an energy model for helping decision making on the construction of a first TTW prototype for its experimental testing and validation. The model is analysed to take advantage of the dynamic behaviour of the TCC to maximize solar energy collection in winter, while reflecting it under summer conditions. The location of Madrid (Spain) is considered suitable for the implementation of the solution. The climatic conditions are those of Mediterranean climate, with warm summers and relatively cold winters. The location is suitable for solar systems testing because it has one of the highest amount of solar irradiation in Europe (Š́ri et al., 2005)..

While traditional solutions are easily evaluated by simple heat transfer equations, a complex energy model is needed to evaluate TTW. In this paper, determining parameters of the operation of the TTW are analysed by energy simulation, such as:

- Changing the surface characteristics of the outer layer, optimizing the use of the variable optical properties of the thermochromic mortar 
- Changing the ventilation rates in the air chamber to modify the wall surface temperature

- Changing the thermal storage and heat transmission capacities for the assumed existing walls.

In this manner most important parameters affecting thermal performance are identified. Also, the thermochromic mortar transition temperature is selected as to achieve maximum efficiency. This analysis is used for the construction of a prototype to be monitored under real climatic conditions. The prototype is located on the city of Madrid, with temperate Mediterranean climate with a continental component. The TTW has been deployed in a test cell situated at the Technical University of Madrid.

\section{METHODS}

The model presented here is studied to define the best theoretical conditions of the TTW prototype. The calculation tool used to model the Trombe wall was EnergyPlus, using DesignBuilder Software v4.7 as an interface. This software does not offer an "object" defined as a Trombe Wall, but it can be modelled combining existing components to handle the needed parameters (Figure 1). The "Type of zone", in the Activity label, was set as "Glazed Chamber". The most accurate solar radiation calculation was selected by "advanced complete interior and exterior solar distribution" algorithms. That way most of the incident solar radiation is registered on the absorbent surface (the wall) and not on the small floor of the air chamber of the Trombe Wall.

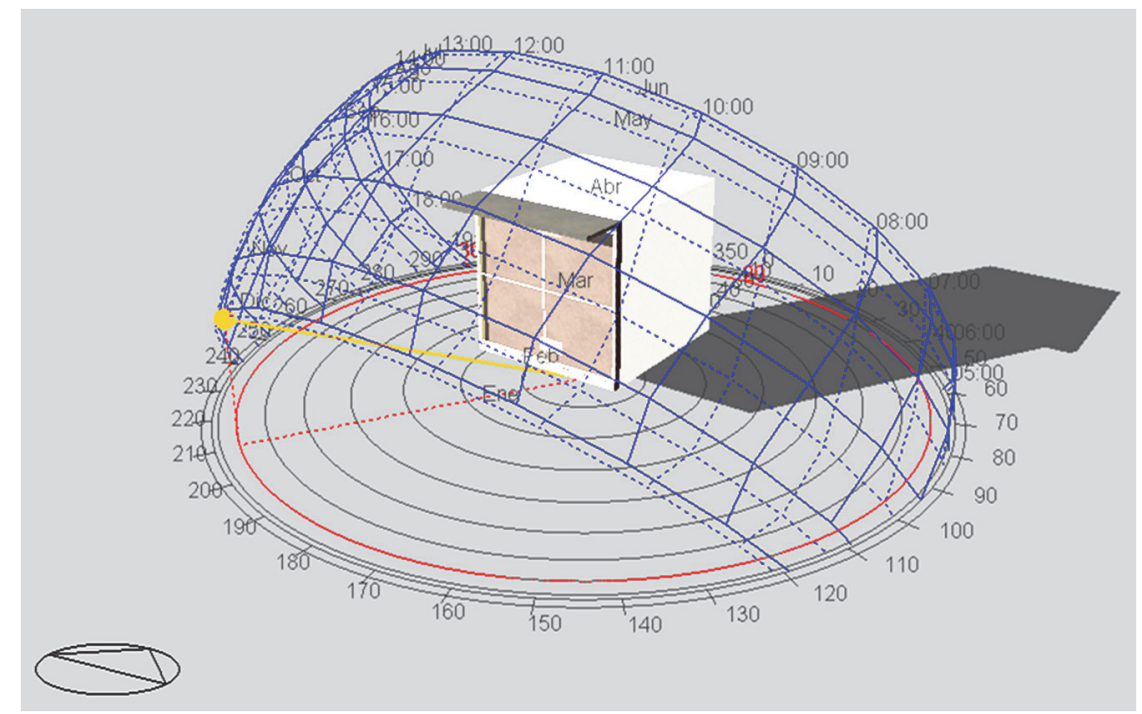

Figure 1. Image of the model under winter conditions

Convection coefficients in the vertical chamber are calculated by attaching a very narrow area (air-gap) to the heated surface as a "glazed chamber". This is possible by using an interzone partition with the constructive characteristics of the existing façade (base wall) (fig. 3). 
A conduction transfer function (CTF) has been used as general calculation algorithm. The most viable option is to use the Detailed Internal Convection Algorithm. This algorithm takes into account, to some extent, the effects of natural convection, but it must be considered that it has been developed for spaces of normal dimensions in architecture. To gain reliability, the calculations of the surface convention coefficients obtained in Table 2 have been introduced in the model. This option seems realistic, since the prototype will be able to control airspeed inside the chamber through the use of fans for forced ventilation.

Gaps and grids where generated modelled in the TTW in two places: on the surface of the glass and on the partition (base wall). The outside grids where programmed in order to be controlled by internal temperatures (generally open when the TTW needs to refrigerate), but the ones in the partition where not able to be programmed. The simulation tool does not permit to control openings in the base wall since it considers it as an internal partition. To avoid this inconvenience heat gains in winter will be evaluated by the convective heat loss through the external air gaps. This permits to compute solar gains through the heat that vents outwards.

Another difficulty for the definition of the model lies in the incorporation of the dynamic properties of the thermochromic coating in the software. This problem has been addressed by carrying out two different simulations: one for winter conditions (January, including high absorbance capabilities of the material) and a second one for the summer (August, including high reflectance surface properties).

\subsection{Geometry}

Geometry of the model is based on the geometry of the prototype. Since the prototype is proposed for Madrid (Spain), in the northern hemisphere, the most favourable orientation to achieve passive solar gains is south. If the glass surface is tilted towards the sun, more solar energy can be captured by the device for maximum conversion. Nevertheless, since this prototype is designed for its incorporation on existing buildings, a vertical solution has been adopted in order to simplify its construction. The dimensions of the modelled façade will be $2,16 \mathrm{~m} \times 2,16 \mathrm{~m}$. The air chamber should be ventilated under monitored controlled conditions. The chosen thickness is $15 \mathrm{~cm}$, in order to have enough space for the installation of fans. Forced ventilation will be useful to control air speed and surface temperature inside the chamber. The total air volume contained is about $0,70 \mathrm{~m}^{3}$

A solar protection is needed in order to avoid unwanted solar radiation during the summer. A fixed upper horizontal sunshade has been chosen. Its dimensions are $70 \mathrm{~cm}$ wide, for the entire length of the facade and located $40 \mathrm{~cm}$ high above the glass surface. This dimensions permit to collect solar radiation in the entire glazed surface during winter solstice at 12:00, while blocking it completely during summer solstice at 12:00. 

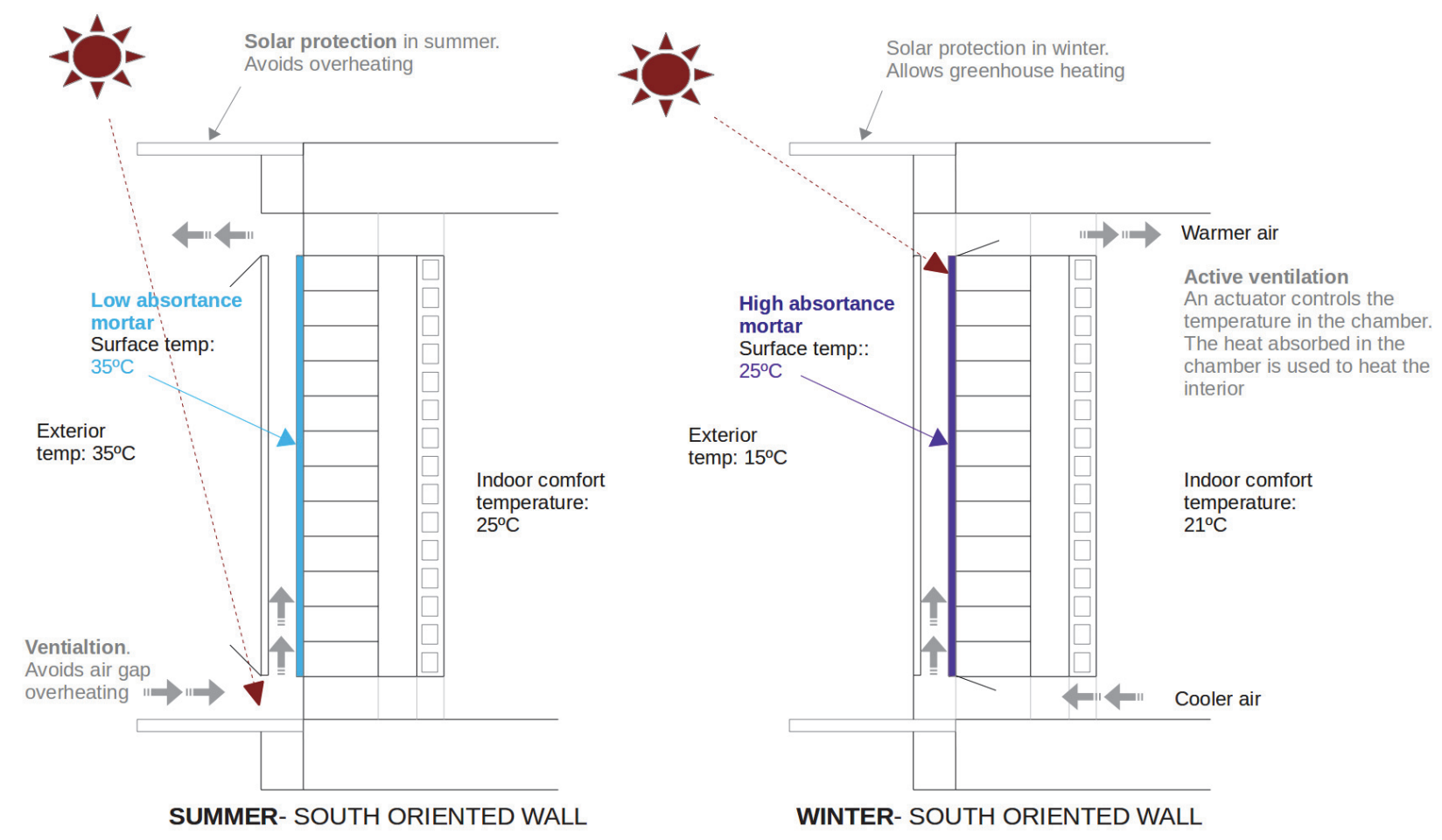

Figure 2: Scheme of summer and winter operation of the proposed system

The prototype includes automatic motorized ventilation gates in both the base wall and on the plane of the glass surface. This is needed in order to control the amount of air renewal into the chamber. The dimensions of these air gaps are $2,16 \mathrm{~m} * 0,10 \mathrm{~m}$, both in the base and the top of the wall. These gates permit to change the system operation according to summer or winter conditions. Figure 2 represents a scheme of summer and winter operation of the proposed system.

\subsection{Constructive components of the Thermochromic Trombe Wall}

The total construction solution is composed by the base wall, the ventilated air chamber and a glass coating. The particularities of the specific application to the TTW are described below:

\section{Base wall}

On a classic Trombe Wall, materials with high heat capacity and high thermal conductivity are used for the base wall. They determine the amount of heat that the system can store and transmission speed by conduction towards the interior space. The base wall (Figure 3), on which the TTW will be displayed, represents a commonly used facade of a multifamily residential Spanish buildings built before 1979. This date marks the entry into force of the first standard that includes the obligation of thermal conditions for buildings. The choice of the solution is based on the conclusions of a previous research project (Oteiza et al., 2015). The configuration 
most frequently found was an $11.5 \mathrm{~cm}$ brick outer wall, a non-ventilated air chamber and a $4 \mathrm{~cm}$ brick partition wall (fig.3). This typology, which prevails in social housing in the city of Madrid, exhibits a number of shortcomings. One is the scant energy efficiency induced by its high thermal transmittance, which ranges from 2 to $1 \mathrm{~W} / \mathrm{m}^{2} \mathrm{~K}$, considerably in excess of the present legal ceiling $\left(0.66 \mathrm{~W} / \mathrm{m}^{2} \mathrm{~K}\right.$ in climates such as Madrid's). On the inside, a plaster lining of approximately $1 \mathrm{~cm}$ thickness has been assumed. On the exterior, the most common coating in these solutions is a cement-sand mortar with a thickness of about $2 \mathrm{~cm}$, which will be covered by the TCC. This coating shows a light colour at high temperatures, associated with a high reflectance (low absorptance) of solar radiation and reversibly changes to a dark colour (low reflectance and high absorptance) when temperature decrease below a certain critical value (Tc).

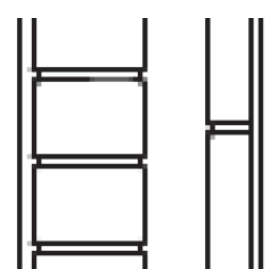

Figure 3: Base Wall section from the typical existing Spanish façade (brick wall + nonventilated air chamber + partition wall)

Simulation of thermochromic effect of the surface of the mortar is introduced into the model by the parametrisation of its absortance (visible and solar) and emissivity as in (Alonso et al., 2017). Two models had to be created, in order to compare different results of separate simulations with light and dark mortars characteristics (Table 1). Also, some typical variations on the composition of the base wall are studied, such as the demolition of the partition wall, or the inclusion of some thermal isolation material on the outer brick wall, in order to determine its influence on the behaviour of the model.

Table 1: Optical properties introduced in the model (\%)

\begin{tabular}{|l|r|r|}
\hline & Light mortar & Dark mortar \\
\hline Visible Absortance & 0,59 & 0,71 \\
\hline Solar Absortance & 0,43 & 0,50 \\
\hline Emisivity & 0,90 & 0,90 \\
\hline
\end{tabular}

\section{Ventilated air chamber}

The external surface temperature of the base wall on the air chamber is an important variable to control changing thermochromic properties of the TCC. Air speed is controlled to achieve the correct refrigeration of TCC surface. An important design premise is that solar radiation must not heat the mortar above the colour change temperature during winter. The heat trapped by the greenhouse effect dissipates into the living space, taking advantage of it as free-heating. The exchange of heat between the thermochromic mortar and the renewal of air in the chamber 
is controlled in the model by the surface convection coefficient. Its calculation in an air chamber is made according to the following equations (1), and the results are shown at table 2:

$$
\begin{aligned}
\mathrm{Hc}=5,8+4,1 * \mathrm{v} \\
\mathrm{Qv}=\mathrm{hc} * \mathrm{~A} * \Delta \mathrm{T} \\
\mathrm{v}=\quad \text { airspeed } \\
\mathrm{hc}=\text { surface convention coefficient } \\
\mathrm{Qv}=\text { heat flow by surface convection } \\
\mathrm{A}=\quad \text { Area } \\
\Delta \mathrm{T}=\text { difference between the surface temperature and the air temperature }
\end{aligned}
$$

Table 2: Calculation of the relation between air change and surface convention coefficient

\begin{tabular}{|l|l|l|l|l|l|l|}
\hline Vol & \multicolumn{2}{|l|}{ Air renovation } & Area & Air speed & surf conv coeff \\
\hline $\mathrm{m}^{3}$ & $\mathrm{R} / \mathrm{H}$ & $\mathrm{m}^{3} / \mathrm{h}$ & $\mathrm{m}^{3} / \mathrm{s}$ & $\mathrm{m}^{2}$ & $\mathrm{~m} / \mathrm{s}$ & \\
\hline 0,7 & 60 & 42 & 0,0117 & 0,32 & 0,036 & 5,95 \\
\hline 0,7 & 120 & 84 & 0,0233 & 0,32 & 0,073 & 6,10 \\
\hline 0,7 & 180 & 126 & 0,0350 & 0,32 & 0,109 & 6,25 \\
\hline 0,7 & 200 & 140 & 0,0389 & 0,32 & 0,122 & 6,30 \\
\hline
\end{tabular}

The proposed solution is the installation of computer fans at the base of the wall. The device formed by a Trombe Wall and the mechanical installation necessary to control the air speed is called "parietodynamic wall". In this case, 5 fans that can be activated (separately or simultaneously) are included on the prototype (Figure 4). Surface temperature sensors placed on the surface of the TCC activate the fans on different speeds.

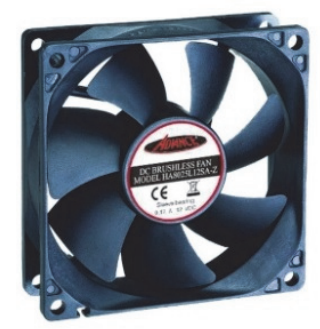

Figure 4: Example of the incorporated fans ${ }^{1}$

\footnotetext{
${ }^{1} \mathrm{https}: / /$ www.pccomponentes.com/ventiladores-cpu
} 


\section{Glazed surface}

Due to the dimensions of the prototype, and for security reasons, a laminated glass has been chosen. More specifically, a double glazing $4+4$ of the type Stadip Color described on (Pérez et al., 2019). The laminated glass has a low transmission in the low wavelength range of the solar spectrum, in order to protect the thermochromic mortar coating from degradation caused by radiation in the range from 250 to $450 \mathrm{~nm}$, as explained in (Perez et al, under revision). This optical behaviour gives rise to a characteristic yellow appearance to the double-glazing implemented in the TTW (Figure 5). The parametrisation of the glazed surface on the model was made by data offered by the commercial supplier (Table 3).

Table 3: Glazing parametrisation

\begin{tabular}{|l|l|}
\hline SHGC & 0,71 \\
\hline Light Transmission & 0,78 \\
\hline Uvalue $(\mathrm{kW} / \mathrm{m} 2 \mathrm{~K})$ & 5,6 \\
\hline
\end{tabular}

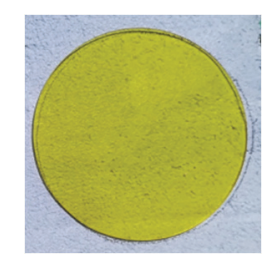

Figure 5: Sample of the selected glass

\subsection{Activity and HVAC}

The model represents a test cell for controlled laboratory conditions, no human occupation is expected. For this reason, no internal or equipment loads have been included in the model. The set point comfort temperatures used for HVAC systems are $20^{\circ} \mathrm{C}$ during the winter period and $25^{\circ} \mathrm{C}$ during the summer period.

The air change in the air gap will be equipped with artificial ventilation, designed to create air flow to reduce the surface temperature of the thermochromic mortar. This will permit to control surface temperature of the thermochromic coating. Since the simulation tool does not permit to control openings in the base wall (this feature is not available for internal partitions), heat gains in winter will be evaluated by the convective heat loss through the external air gaps.

The interior space of the cell, whose habitability conditions will be monitored, will have no air exchange apart from the air coming from the ventilated air chamber of the TTW. Cells are equipped with heating/cooling facilities, which permit to store data about energy consumption. A wider description of the HVAC systems can be found at previous publications related to other experiments tested (Alonso et al., 2016). 


\subsection{Parametrical analysis}

Table 4 collects the main parameters considered in the 10 cases addressed in the parametric analysis. Different possibilities for wall properties (both mortar colour and wall composition) and ventilation rates in the air chamber are analysed. The aim is to assess their influence over the system seasonal performance.

Table 4: Description of the parameters for each case

\begin{tabular}{|c|c|c|c|c|}
\hline Case N. & name & mortar & Vent. (h-1) & Wall composition \\
\hline 1 & mCl_15cm_Vforz120_cEA & light & 120 & Existing \\
\hline 2 & $\mathrm{mCl} \_15 \mathrm{~cm} \_V$ Vforz180_cEA & light & 180 & Existing \\
\hline 3 & $\mathrm{mCl} 15 \mathrm{~cm}$ _Vforz200_c1h & light & 200 & one layer \\
\hline 4 & $\mathrm{mCl} 15 \mathrm{~cm}$ _Vforz200_cEA & light & 200 & Existing \\
\hline 5 & $\mathrm{mCl} 15 \mathrm{~cm} \_V$ Vforz200_cEPS & light & 200 & insulated \\
\hline $\mathbf{6}$ & mOs_15cm_Vforz120_cEA & dark & 120 & Existing \\
\hline $\mathbf{7}$ & mOs_15cm_Vforz180_cEA & dark & 180 & Existing \\
\hline $\mathbf{8}$ & mOs_15cm_Vforz200_c1h & dark & 200 & one layer \\
\hline $\mathbf{9}$ & mOs_15cm_Vforz200_cEA & dark & 200 & Existing \\
\hline $\mathbf{1 0}$ & mOs_15cm_Vforz200_cEPS & dark & 200 & insulated \\
\hline
\end{tabular}

3 different wall compositions have been simulated in the model in order to analyse the influence of the base wall in the system. The first one is the typical existing wall in Spain (Figure 3) without any modification except the addition of the TCC. The second wall composition eliminates the interior partition wall (one layer- with hig Uvalue)). A third possibility is included in the parametric analysis: the addition of an external thermal insulation system (ETIC) on the one layer wall (lo Uvalue).

The evaluation of the efficiency of the TTW will be done by the analysis of the variables that determine the optical characteristics of the TCC and the energy efficiency of the system (Figure 6):

- SURFACE_WALL_T: External surface wall temperature. The data is obtained from the base wall, situated between the ventilated air chamber and the inhabited space inside the test cell. In the results table (Table 5), both surface temperatures from the base wall are represented: the outside is the temperature of the TCC, and the inside is the surface that radiates heat into the test-cell.

- INT_CONSUMPTION: Space heating and cooling energy consumption. The data is obtained inside inhabited space (test cell).

- TROMBE_SENS_HEAT: Sensible heat gains in winter, inside the TTW ventilated air chamber. 


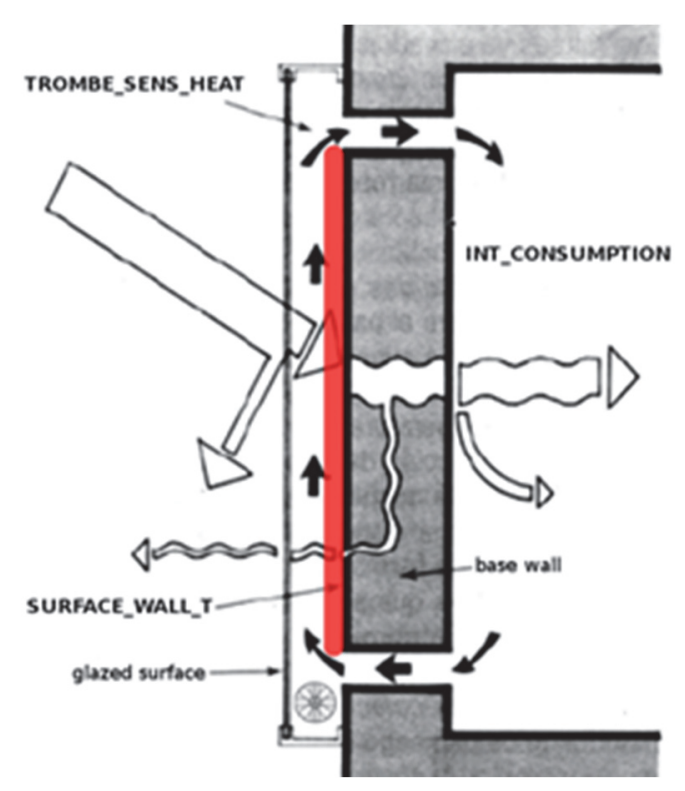

Figure 6: Variables used for the evaluation of results. Modified from (Izard and Guyot, 1980)

\section{RESULTS}

Once the energy simulation is performed for each one of the cases, detailed results are collected for each solution. Figure 7 shows an example (case $\left.n^{\circ} 9\right)$ of the data obtained for each combination of parameters. It shows results on the annual data and for the coldest and the warmest month in Madrid for the three chosen variables (INT_CONSUMPTION, TROMBE_SENS_HEAT and SURFACE_WALL_T).

Surface wall temperature (SURFACE_WALL_T) is the most important variable to control the colour change temperature of the TCC. This temperature depends on a balance between ventilation in the air chamber, the need of heat in winter (with dark colour-low temperature TCC) and the reflection of solar radiation during the summer (for which the mortar must keep light colour-high temperature). In Madrid latitude, high solar radiation during the winter season on south orientation façades complicates the equation. Solar protection acts seasonally to protect the mortar from solar radiation during the summer. The ventilation control inside the chamber allows adjusting the temperature of the mortar surface.

Energy consumption (INT_CONSUMPTION) is the variable that permits to evaluate energy performance during the summer (cooling consumption) while sensible heat gains (TROMBE_SENS_HEAT) is an adequate variable to evaluate performance during the winter. 

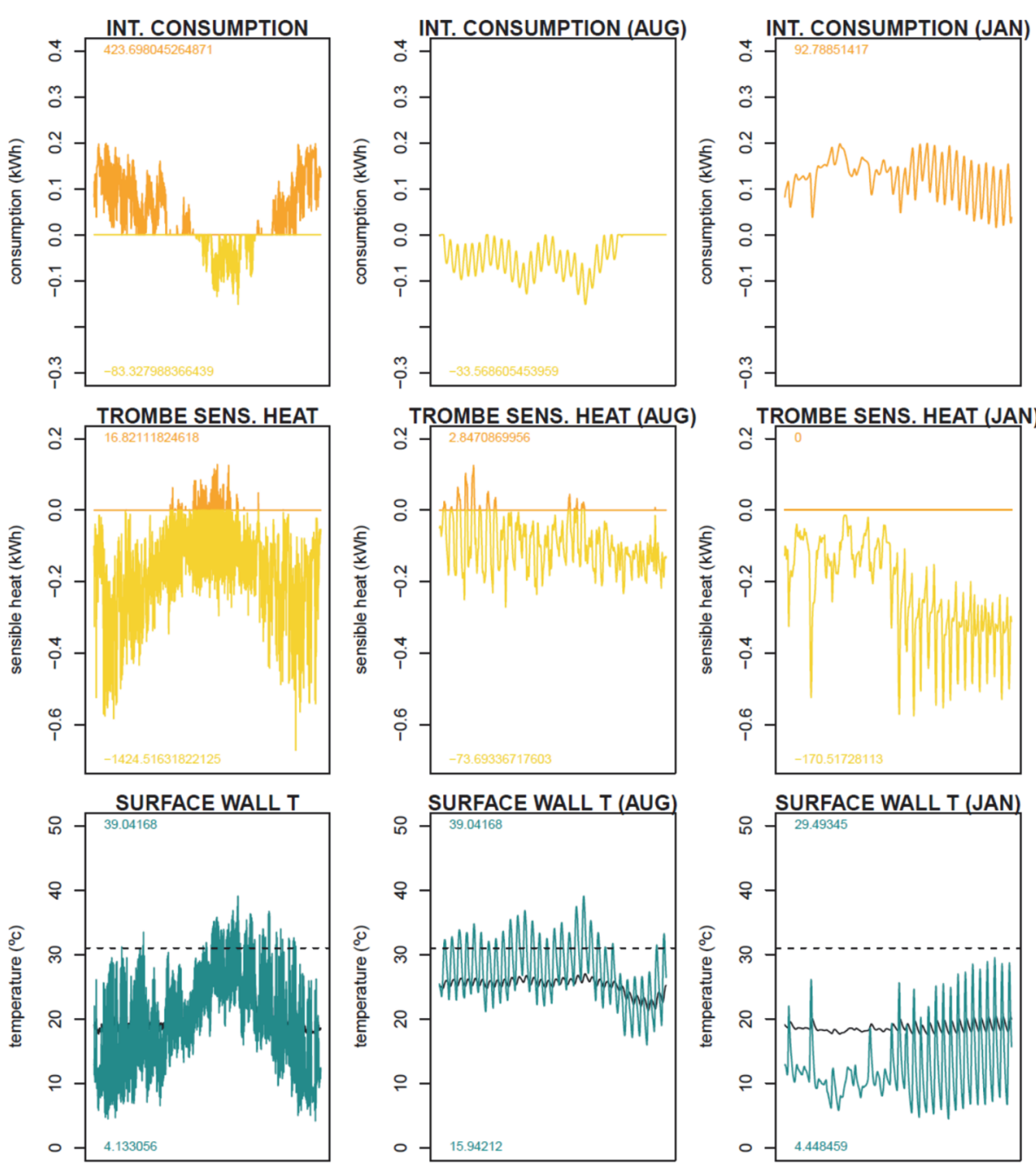

Figure 7: Example plot of detailed results for case number 9: yearly and monthly data (August and January)

Main results obtained for each simulated case are shown in Table 5. Results for January represent winter conditions (assuming dark properties of the TCC) and August results are used to analyse summer conditions (assuming light colour properties of TCC). Cooling energy consumption is directly obtained by the results of the simulation. For the calculation of heating consumption, solar gain contribution to the energy demand is accounted through the "sensible heat loss" estimation through the ventilated air chamber.

Table 5: Main results for each simulated case

\begin{tabular}{|c|c|c|c|c|}
\hline Case N. & $\begin{array}{c}\text { Cooling } \\
\text { consumption. } \\
\text { Indoor }(\mathrm{kWh})\end{array}$ & $\begin{array}{l}\text { Sensible heat loss. } \\
\text { Airgap (kWh) }\end{array}$ & $\begin{array}{c}\text { Wall surface temperature } \\
\qquad\left({ }^{\circ} \mathrm{C}\right)\end{array}$ & $\begin{array}{l}\text { Surface heat } \\
\text { loss (kWh) }\end{array}$ \\
\hline & august & \begin{tabular}{l|l} 
august january & ja
\end{tabular} & january & \begin{tabular}{l|l} 
august & january \\
\end{tabular} \\
\hline
\end{tabular}




\begin{tabular}{|c|c|c|c|c|c|c|c|c|c|}
\hline & & & & $\max$ & $\min$ & $\max$ & $\min$ & & \\
\hline 1 & $-23,15$ & $-54,18$ & & 40,72 & 14,93 & 32,43 & 3,35 & $-20,73$ & 45,53 \\
\hline 2 & $-22,31$ & $-58,46$ & & 40,61 & 14,57 & 31,45 & 2,77 & $-19,78$ & 49,05 \\
\hline 3 & $-36,88$ & $-51,26$ & & 39,80 & 14,70 & 32,45 & 4,24 & $-33,43$ & 84,41 \\
\hline 4 & $-22,13$ & $-59,40$ & & 40,59 & 14,49 & 31,24 & 2,65 & $-19,57$ & 49,82 \\
\hline 5 & $-10,70$ & $-66,40$ & & 41,31 & 14,31 & 33,17 & 1,30 & $-7,86$ & 18,97 \\
\hline $\mathbf{6}$ & 23,93 & & $-125,32$ & 41,05 & 15,04 & 33,50 & 3,42 & $-21,6$ & 43,88 \\
\hline $\mathbf{7}$ & $-23,05$ & & $-135,73$ & 40,92 & 14,63 & 32,48 & 2,84 & $-20,6$ & 47,47 \\
\hline $\mathbf{8}$ & $-38,12$ & & $-159,42$ & 40,09 & 14,77 & 33,43 & 4,27 & $-34,8$ & 82,24 \\
\hline $\mathbf{9}$ & 22,86 & & $-138,00$ & 40,90 & 14,56 & 32,26 & 2,71 & 20,38 & 48,25 \\
\hline $\mathbf{1 0}$ & $-10,97$ & & $-119,52$ & 41,64 & 14,37 & 31,23 & 1,40 & $-8,22$ & 18,28 \\
\hline
\end{tabular}

Conduction heat loss is higher for cases $3(-33,43 \mathrm{kWh}$ in August) and $8(82,24 \mathrm{kWh}$ in January). Concerning the wall composition these are the cases with a single uninsulated layer. This solution has the lowest thermal quality so higher heat transmission (Uvalue). Even though, during the summer conduction is also high for this wall composition, causing higher unwanted cooling consumption $(-36,88 \mathrm{kWh}$ in case 3$)$.

In summer the light coloured mortar has also a positive effect in cooling consumption, improving from $2,5 \%$ in the one layer wall to $3,2 \%$ for the insulated wall.

The dark mortar has an influence on conduction gains. In august it would increase $4 \%$ and $3 \%$ in January. The mortar colour change will therefore have a positive effect in this conduction transfer, reducing the heat gain in august and increasing it in January.

In January the maximum surface temperature does not exceed $31^{\circ} \mathrm{C}$. So this could be considered as the adequate critical value for transition of the optical solar response of thermochromic mortar.

In August the maximum temperature in the wall surface is $41,6^{\circ} \mathrm{C}$ for case 10 , but the differences are not significant for all cases. This maximum is coincident with the highest outdoor temperature, as so the minimum is registered at night.
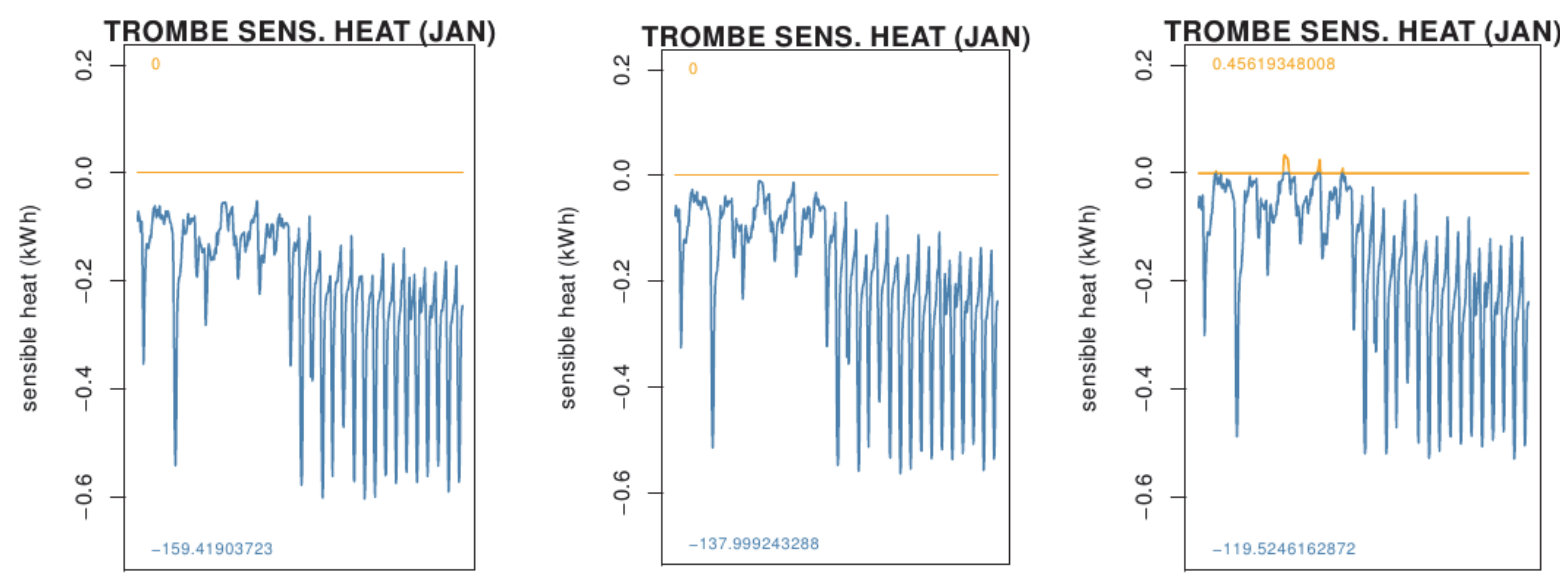

Figure 8: Sensible heat gain in cases 8 (one layer), 9 (existing), 10 (insulated) 
The sensible heat loss in the air gap is much higher in winter than in summer in all cases. As it is said in the simulation configuration, this heat loss would represent the heat gains by convection for heating the indoor environment in winter conditions (Figure 8). Solar radiation uptake by the vertical surface is higher due to the sun path, achieving high passive gains that increase with the ventilation rate, as the convection heat transfer is higher. It is also higher for the one layer wall, as the exterior wall surface temperature is also higher. Ventilation rate causes a variation that goes from $125,32 \mathrm{kWh}$ (case 6) to $138 \mathrm{kWh}$ (case 9) for the same base wall composition. The results about the energy delivered by convection by the TTW (Figure 9) show that preheated air is higher while Uvalue of the base wall is lower. However, conduction through the wall is reduced by increasing the quality of the enclosure. Concerning conduction, higher ventilation rates also causes higher heat loss that vary from $43,88 \mathrm{kWh}$ (case 6 ) to 48 , $25 \mathrm{kWh}$ (case 9).

\section{CONSTRUCTION OF THE PROTOTYPE}

The Thermochromic Trombe wall (TTW) was constructed in a test cell situated under monitored external climatic condition sited at Universidad Politécnica de Madrid, in Montegancedo Campus. The prototype is constructed in order to gather data under real weather conditions and different environmental control profiles.

The wall composition chosen for the prototype was the typical base wall composition. This composition gets better sensible heat gains than the one-layer wall, and better conduction gains than the insulated one. Also, the incorporation of the system in an existing building will be easier if the base wall is not affected.

A wooden solution has been chosen for the frames in order to promote the development of construction systems with the lowest environmental impact. Its behaviour on real climatic conditions and the deterioration of the materials will be analysed in order to ameliorate the design, facing the conceptualization of an endurance long term constructive system. The constructive system definition for the final solution of the TTW prototype was designed by an architecture office in Madrid (taBIM architecture) (Figure 9). 

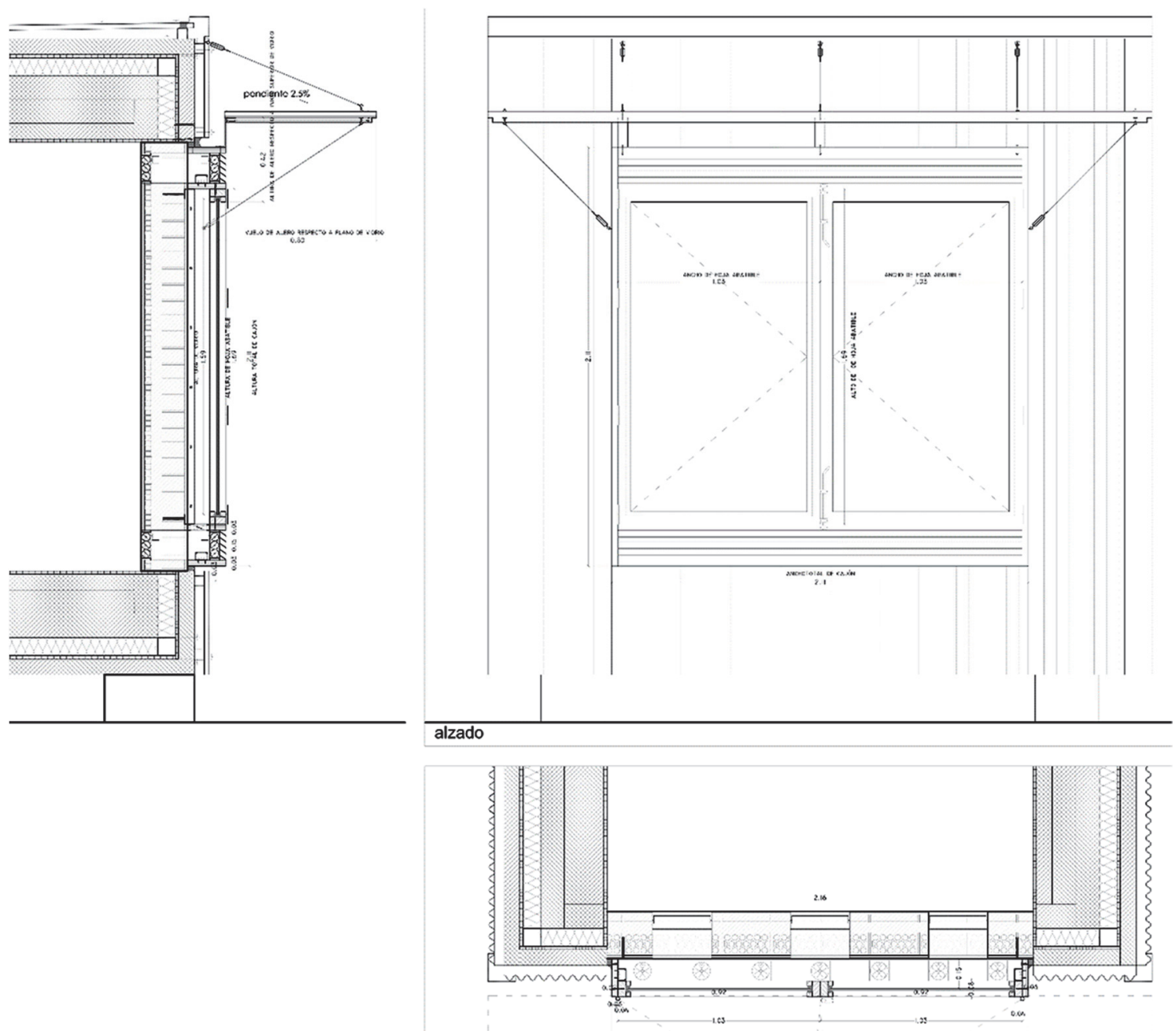

Figure 9: Constructive definition: Floor plan, section and elevation (Botella, 2018) 


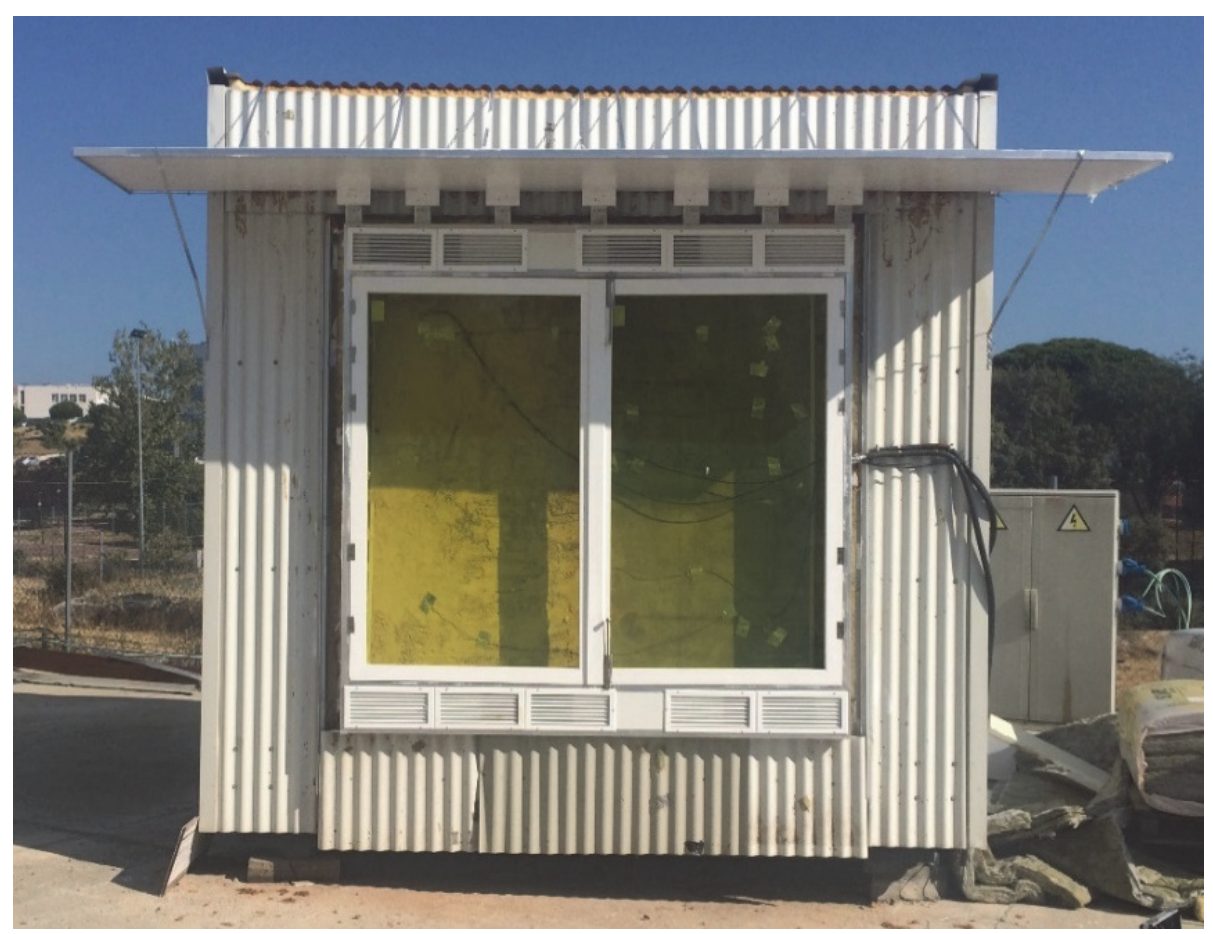

Figure 9: (1) Image of the constructed prototype (M2)

The construction of the prototype was started on the summer of 2018, and the installation of the thermochromic tiles during the autumn (fig. 9). The monitoring system for data collection was then adjusted and started registering data during the winter.

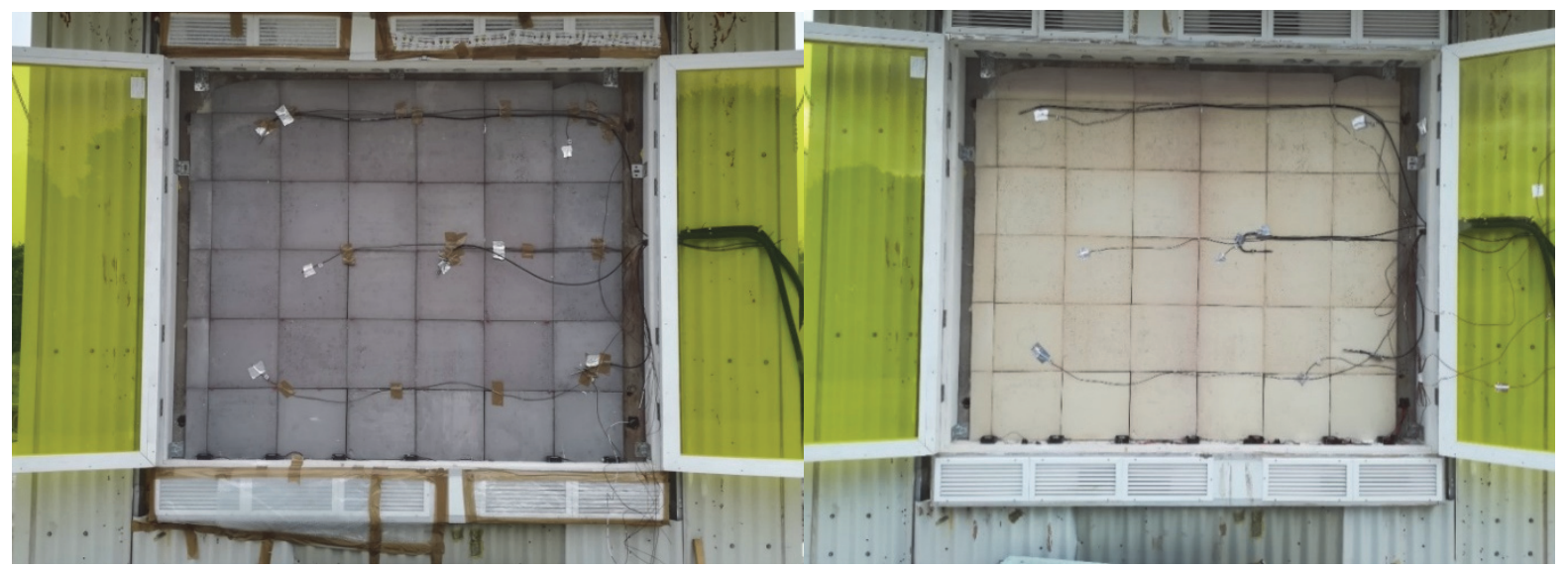

Figure 10: Detail of the thermochromic tiles in (2) high absortance and (3) high reflectance mode

\section{CONCLUSIONS}

An energy model has been proposed and used for the optimisation of the design of a TTW. This model was useful to analyse different parameters that can impact on the performance of Trombe Walls. The effect of changing surface properties of the thermochromic coating is 
analysed by comparing different simulations for summer or winter conditions. The model confirms that Trombe walls including controlled ventilation in the air are a suitable solution to incorporate thermochromic coatings in south orientation. The solution permits to take advantage of the thermochromic properties and keep high absortance during the winter even under high solar radiation situations.

Colour change has an influence in the seasonal performance, reducing winter heating demand by the higher uptake of solar radiation caused by the increase of the absorptance of the surface of the wall. During the summer, heat gains are reduced by the increase of its reflectance. To maximize this effect, mortar temperature for changing the colour should be fixed around $30^{\circ} \mathrm{C}-31^{\circ} \mathrm{C}$. An experimental model under real conditions is required in order to precisely determine energy savings.

Results show clearly that airspeed on the ventilated air chamber (Table 2) has to be the highest of the modelled options $(200 \mathrm{R} / \mathrm{H})$, for all of the three studied base wall compositions. This is needed to keep the external surface of the TCC under the limiting temperature during the winter, absorbing high solar radiation on south orientation. For the prototype construction, 5 ventilators have been installed.

High rates of ventilation in the air chamber refrigerate the external coating. This decreases its temperature, causing the decrease of the heat stored in the existing wall. Since heat obtained by transmission is lower than in a conventional Trombe wall, the heat obtained by ventilation prevails.

Conduction heat gain is higher for uninsulated single layer wall composition, since conduction through the wall is reduced by increasing the quality of the enclosure. Insulated walls are not optimal for colour change control of the TC coating, since they reach higher temperatures than non-insulated walls during the winter. This circumstance makes uninsulated old existing buildings suitable for the application of the TTW technology.

The parameters studied on this paper are useful for its construction, and collected data will permit to validate the design, and/or introduce modifications based on scientific evidences. An experimental model has been constructed in order to precisely determine energy savings potential detected by the simulation. Monitored data under real climatic conditions will be registered during one year, and will be observed during winter and summer conditions. The results from one-year monitoring of the test cell under real climatic conditions will be used to design a final prototype. The weakness observed on the experimental test will be noted for improvement. The existing parametric model will be calibrated using real performance and registered climate data. This will permit to evaluate required improvements with a higher precision, in order to design a final prototype with the best performance.

\section{FUTURE RESEARCH LINES}

Based on the empirical results, the possibility of including different improvements to the prototype will be analysed. For example, the programming of hybrid ventilation by the correct use of gates. The introduction of fresh air inside the inhabited space will guarantee the necessary renovations to keep indoor environment healthy. Concerning the renovation of indoor air through ventilation across the air chamber, this concept would be especially interesting during 
the winter, when outdoor air can be preheated through the glazed chamber before its impulsion into the indoor space. Fresh air introduction from the outside would produce an overpressure that could reduce unwanted infiltration of air through the envelope. Scheduling of the gates could be programmed so that the necessary amount of air can be introduced every hour in order to ensure the renovation and healthiness of indoor air. In addition, some filters and devices for air purification can be introduced in the ventilated air chamber.

The conception of solar water heater integrated in a building façade has been proposed in Tunis by the integration of a water heater on building's facade. By an integrated storage solar collector and the thermosiphon circulation of water the heat can be stored in a deposit (Ben Slama and Ellasoued, 2018). These ideas could be incorporated to a future TTW prototype in order to take advantage of the heat storage capacity of water without adding too much weight on the façade. Water could be used for DWH as proposed in Tunis, but also for low temperature radiative space heating systems that could ameliorate storage capacity and comfort in comparison to the traditional air heating system. A hydronic circuit included in the wall of mass, for heating and water transportation by using solar thermal energy will be studied.

The inclusion of solar PV panels in the shading device for electricity generation that could be used for refrigeration on the summer, when maximum solar radiation will impact in the solar protection, enhancing the performance of the system.

Changing the surface emissivity could also help to increase energy efficiency. To achieve this purpose, the coating could dissipate heat during the summer by adopting high emissivity, and contribute to heat conservation during the winter by adopting low emissivity characteristics.

\section{ACKNOWLEDGEMENTS}

This work is part of the tasks developed for the project BIA2014-56827-R "Development of an intelligent coating mortar based on thermochromic ecoefficient cements (MICET) " funded by Spanish Ministry of Economy, Industry and Competitiveness. The construction system analysis was produced under funding of the Spanish Ministry of Economy and Competitiveness project BIA 2017-83231-C2-1-R: "HABITA-RES: Nueva herramienta integrada de evaluación para áreas urbanas vulnerables. Hacia la autosuficiencia energética y a favor de un modelo de habitabilidad biosaludable".

\section{REFERENCES}

Alonso, C., Martín-Consuegra, F., Oteiza, I., Asensio, E., Pérez, G., Martínez, I., Frutos, B., 2017. Effect of façade surface finish on building energy rehabilitation. Sol. Energy 146, 470-483. https://doi.org/10.1016/j.solener.2017.03.009

Alonso, C., Oteiza, I., García-Navarro, J., Martín-Consuegra, F., 2016. Energy consumption to cool and heat experimental modules for the energy refurbishment of façades. Three case studies in Madrid. Energy Build. 126, 252-262. https://doi.org/10.1016/j.enbuild.2016.04.034 
Ben Slama, R., Ellasoued, R., 2018. Conception of Two Wall-Solar Water Heater. Innov. Energy Res. 07. https://doi.org/10.4172/2576-1463.1000202

Botella, F., 2018. Project of constructive definition for the assembly of a prototype for a thermochromic thrombo wall.

Chen, B., Chen, H.J., Meng, S.R., Chen, X., Sun, P., Ding, Y.H., 2006. The effect of Trombe wall on indoor humid climate in Dalian, China. Renew. Energy 31, 333-343. https://doi.org/10.1016/j.renene.2005.04.013

European Parliament and UE Council, 2012. Directive 2012/27/EU of the European Parliament and of the Council of 25 October 2012 on energy efficiency, amending Directives 2009/125/EC and 2010/30/EU and repealing Directives 2004/8/EC and 2006/32/EC Text with EEA relevance, 315.

Kaushik, S.C., Kaul, S., 1989. Thermal comfort in buildings through a mixed water-mass thermal storage wall. Build. Environ. 24, 199-207. https://doi.org/10.1016/03601323(89)90033-4

Martín-Consuegra, F., 2012. Soluciones constructivas para rehabilitación energética de edificios existentes: Muros Trombe.

Mazei, E., Serra Florensa, R., 1985. El libro de la energía solar pasiva. Gustavo Gili, México.

Mohamad, A., Taler, J., Ocłoń, P., 2019. Trombe Wall Utilization for Cold and Hot Climate Conditions. Energies 12, 285. https://doi.org/10.3390/en12020285

Oteiza, I., Alonso, C., Martín-Consuegra, F., González-Moya, M., Monjo, J., 2015. Energy Retrofitting for Social Housing by Improving the Building Envelope: Madrid, 19391979.

Oteiza, I., Carmen Alonso, Fernando Martín-Consuegra, Juan Monjo, Mariam González Moya, Alberto Buldón, 2018. La envolvente energética de la vivienda social. El caso de Madrid en el periodo 1939-1979, Monografías del IETcc. Serie Arquitectura. Instituto Eduardo Torroja de ciencias de la construcción, Madrid.

Özbalta, Kartal, n.d. Heat gain through Trombe wall using solar energy in a cold region of Turkey [WWW Document]. URL (accessed 10.1.18).

Pérez, G., Allegro, V., Gavira, M.J., Alonso, C., Martín-Consuegra, F., Oteiza, I., Frutos, B., Guerrero, A., 2019. Selection of suitable materials for the development of an innovative thermochromic trombe wall. Presented at the 2nd RILEM Spring Convention \& International Conference on Sustainable Materials, Systems and Structures, Rovinj, Istria (Croatia).

Saadatian, O., Sopian, K., Lim, C.H., Asim, N., Sulaiman, M.Y., 2012. Trombe walls: A review of opportunities and challenges in research and development. Renew. Sustain. Energy Rev. 16, 6340-6351. https://doi.org/10.1016/j.rser.2012.06.032

Torcellini, P., Pless, S., 2004. Trombe Walls in Low-Energy Buildings: Practical Experiences Preprint.

Yu, B., Hou, J., He, W., Liu, S., Hu, Z., Ji, J., Chen, H., Xu, G., 2018. Study on a highperformance photocatalytic-Trombe wall system for space heating and air purification. Appl. Energy 226, 365-380. https://doi.org/10.1016/j.apenergy.2018.05.111

Zhang, X., Lau, S.-K., Lau, S.S.Y., Zhao, Y., 2018. Photovoltaic integrated shading devices (PVSDs): A review. Sol. Energy 170, 947-968. https://doi.org/10.1016/j.solener.2018.05.067

Zhou, Y., Wah Yu, C., 2019. The year-round thermal performance of a new ventilated Trombe wall integrated with phase change materials in the hot summer and cold winter region 
of China. Indoor Built Environ. 28, 195-216. https://doi.org/10.1177/1420326X18807451 